\title{
Youth in the margin in Morocco: a qualitative approach to the perception of subjectivity and agency politics
}

\author{
Ilham Sadoqi, * \\ ${ }^{1}$ Cultural Studies, Languages and Communication Department, ENSAM Rabat, Mohammed V \\ University, Rabat, Morocco
}

\begin{abstract}
This paper seeks to investigate the potentials of youth agency in the margin of society and understand the prospects for social action or "Hirak" as an ongoing sweeping protest wave of a marginalized population. Based on a national qualitative study about youth and marginality in Morocco, this paper will focus on three moments. First, it will examine youth perception, their representation of their subjectivities, and how the realities and experiences of exclusion and "Hogra" manifested in inequalities, injustice, and systematic violence have shaped their beliefs and desire to act. The second moment brings to the fore their apprehension of the hegemonic powers of state institutions and social actors to determine their motivations and initiatives to articulate their actions locally and nationally under conditions of domination. The third moment will shed light on the dynamics of youth agency and the nature of their actions, be it individual or collective, subjective or rational. Similarly, it will also consider the structural limitations impinging on the social, political, cultural life, and gender relations. This paper examines the relationship between youth agency in the margin and the emergence of a new quest for social action "Hirak" in different regions of Morocco and how this might pave the way towards renegotiating the existing social contract between society and state.
\end{abstract}

\section{Introduction}

Youth demographic size and their massive involvement in protest movements have rendered the youth factor at the heart of researchers and decision makers' focus recently. State institutions have adopted various recent reforms and measures to enhance youth inclusion. Some dispositions of the constitution of 2011 call for the state's commitment to promoting youth participation in public life, leading to an integrated national strategy of youth in 2014. Despite these significant advances, better integration of youth and a remarkable decrease of exclusion and violence(s) they face constitute a challenging matter.

According to the High Commission of Planning's study report in 2019, 28\% of Moroccan youth between 15 and 24 years old were unemployed [5]. 27.9\% were considered NEET in 2017 because they did not receive any form of education, employment, and training [6]. Beyond this age, young people could not benefit from governmental youth-based programs because of the predefined age criterion. Consequently, decision-makers seem to prioritize the socio-economic dimension in their youth-oriented public policies. Their perspective reflects their unresponsiveness to the multidimensional and accumulative nature of youth marginalization. Therefore, the integration of youth in the margin into the job market constitutes their overriding strategy for social inclusion. Unfortunately, these integrationist programs discuss on occasions how to grabble with their political and cultural exclusion. This 'economistic' approach to integration seems to be social stability-oriented. 


\subsection{Conceptualizing youth in Morocco:}

Youth as a demographic multitude seems to be a sociologically and culturally under-studied category. Most studies on youth underscore their value system, economic condition [22, 14], or social potential for change through collective agency [25]. Other works conceptualize this category as a « confusingly » depoliticized mass [2, 26]. Paradoxically, the post-Arab Uprising condition has unveiled new tendencies. They concern both youth's apparent "disavowal of conformist modes of expression and a creative apprehension of identity politics in the public sphere" [10]. Such drive towards more visibility and agency might indicate new cultivation of a culture of 'independence' or 'distance' from the dominant status quo. Therefore, this paper questions how youth representation in the margin and their agency politics inform each other.

In the aftermath of the Arab Uprisings of 2010/11, youth's contentious activities have ranged from street demonstrations to sit-ins against government unemployment policies to organized strikes [20] and new protest movements like the Rif movement or Hirak [22]. In 2019 the boycott campaign gave rise to new dynamics of protest culture. Despite the continuing scholarly interest in top-down approaches foregrounding the authoritarian resilience of institutions [23], bottom-up approaches have brought into light the role of young people $[12 ; 7,1]$ and their motivations for political mobilization. Few other scholars adopted an interactionist approach linking the structure of the system and contingency [19]. Through this outlook, they elucidated the dynamic relationship between youth contestation and the role of the regimes in nurturing or obliterating political opportunities for participation from below $[23,26]$.

In Morocco, empirical research on youth in the margin has not been significant; therefore, this paper tries to interrogate the links between youth, exclusion, and agency politics. The study employs youth exclusion as an analytical category and an operational concept to apprehend the diversity of social situations and complex trajectories of youth and their effect on the representations of their subjectivity and prospects of their agency. Such marginalized category refers to an unemployed graduate, single mother, or a young person with an extremist movement/radical ideology. The margin, be it a choice or a subdued condition, is invariably imbued with power dynamics. It often offers a space to question the dominant social norms constructed by a' center', which constitutes a site of the production and circulation of power and meaning to distribute privileges and sustain the established normative system.

This study sheds light on the possible dynamics between the center and the margin to determine the ways youth in the margin negotiate convictions, subjectivities, ideologies, and agency. This paper delves into the possible connections between youth's political, cultural, and socio-economic facets of exclusion on the one side and their agency on the other. It equally investigates youth perception of their subjectivity and how they allot meanings to the realities of their exclusion.

\subsection{Methodology}

The qualitative research co-conducted for this study is part of a national survey on youth, marginality, and violence (with the Rabat Social Studies Institute). The data comes from focus groups and interviews conducted in seven representative regions between May and June 2016. Eighteen focus groups occurred in Rabat, Casablanca, Marrakesh, Fes, BeniMellal, Oujda, and Tangier regions. The selection criteria regarded other factors like the type of exclusion (socio-economic, cultural, and political), the milieu (rural, urban, and semi-urban), and gender to test the hypothesis and ensure the necessary external diversity and internal homogeneity. Besides, ten semi-structured interviews in each region have 
endowed the data with in-depth details of the realities of youth marginalization and the prospects for actuating change.

The sample consists of $34 \%$ of young women and $66 \%$ of young men. Despite the challenge of gender equity, a selective sampling aims to ensure gender balance and the inclusion of individuals, as women's participation is contingent on the time and the place of focus groups. Most marginalized young women seem to have limited access or less preference to public spaces. The majority of participants in focus groups and interviews were between 18 and 30 years old. Other profiles judged informative are more than 35 , although representing only $2 \%$ of the sample. Concerning family status, $30 \%$ were single, $27 \%$ with a partner, $6 \%$ were married, and $5 \%$ were divorced. The study considered three categories of focus groups and interviews based on the typology of marginality. The first one focused on youth's political exclusion and their activism within leftist political parties like Unified Social Party (PSU), extreme left (Democratic Path), contestation movement like 20 February, Islamist, students movement, and Amazigh movement, unemployed graduates associations, activists in human rights associations like the Moroccan Association of Human Rights (AMDH), committees of anti-high living costs, e-activists, critical humor bloggers. Participants without interest in politics complemented this sample. The second category on youth socio-economic marginality included temporary workers, farmers, underpaid workers like street vendors, 'ferrasha' housemaids, servers, parking lot guardians. The third category on youth's cultural marginality comprised those who chose or had to present cultural activities without the social support of the institutions of socialization, the state, or the private sector. Other participants resorting to informal modes of artistic practice like street art, rap, graffiti, and street theatre enriched this sample.

These sampling factors of exclusion type, demography, geography, gender, cultural difference, and activism are essential to elucidate the divergences and similarities in the attitudes and perceptions of the marginalized youth in Morocco. This paper aims to investigate youth's perceptions of their subjectivity, identify their participation in the public sphere, and analyze the transformative power of youth agency on society.

\section{Perception of youth}

Youth designates a social category that escapes strict categorization in sociological studies. The study perceives youth as a heterogeneous group in Bourdieu's sense, in their attitudes, behaviors, worldviews, or aspirations. It unveils the need to question definitions of young age that foreground biological, administrative, or statistical criteria. The lifeworld of youth exclusion as experienced in everyday subjectivity discloses a difficulty to ensure this passage towards stable and durable integration in adult age. Other age-based concepts portray youth in 'relational' terms through a contrastive relationship between childhood and adulthood $[19 ; 14,18]$. Nevertheless, young people undergo evolutionary trajectories with change-induced fragility. Within the realities of exclusion, youth construct and/or reconstruct their worldviews vis-à-vis the dominant social norms and the institutions of power.

Against monolithic approaches, this study draws on a constructivist approach to youth in the margin by examining how they perceive their subjectivity and the realities of their exclusion. To analyze youth representation of their subjectivities under the framework of marginality does not insinuate a reduction of this social category only to problems. Their modes and experiences of resistance and agency politics are as important as factors causing exclusion and violence.

As the data in the three types of focus groups and interviews demonstrate using qualitative data analysis software, the representation of Moroccan youth seems to evade 
different sociological definitions based merely on age or economic independence considerations. They perceive themselves within a multidimensional, plural, and contextbound understanding of youth by referring to varied demographic criteria of education, area, affiliations, and gender factors.

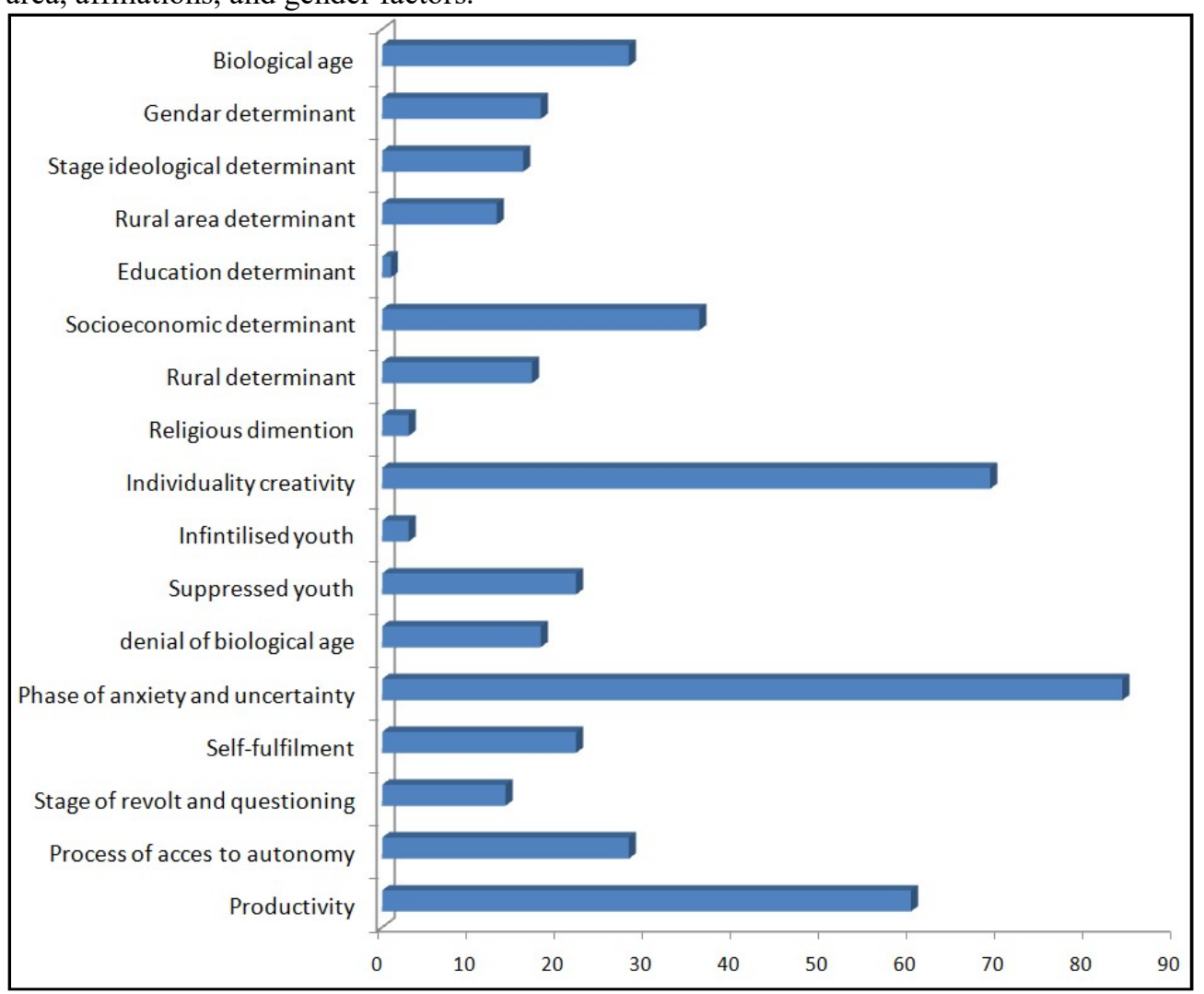

Fig. 1 Representations of youth in the margin

Youth designate a phase of anxiety and uncertainty, which might indicate their rejection of the lack of opportunities to affirm themselves as active agents of society in various sectors of action and production. This kind of assumption might justify their multifaceted exclusion from the circle of power and money. They do not benefit from economic opportunity and active participation in governing their public affairs. Similarly, youth inclusion into the socio-cultural spaces to manufacture the rules that regulate social systems and norms seems to be tightly restrained. Accordingly, the unclear and un-promising existing social project and youth's lack of the material and the symbolic means to act against their marginalization empowered their agency. They have revoltingly increased their individuality instead of falling victim to self-effacement. Such trajectory can indicate a withdrawal from collective identity and a celebration of alternative modes of action to deal with the constraints of their lifeworld and the system. Resistance is liable to take more radical manifestations demonstrated by the recent protest movements of the boycott campaign and the Rif Hirak. The study has revealed how the marginalization of the young generation could generate new channels to voice for their needs, aspirations for justice, dignity, and access to the means of power. 


\section{Youth subjectivities in the margin}

To apprehend the underlying motivations, the analysis of the living conditions of young people subduing socio-economic, political, or cultural exclusion clearly illustrates the dominance of their anxious and uncertain subjectivities.

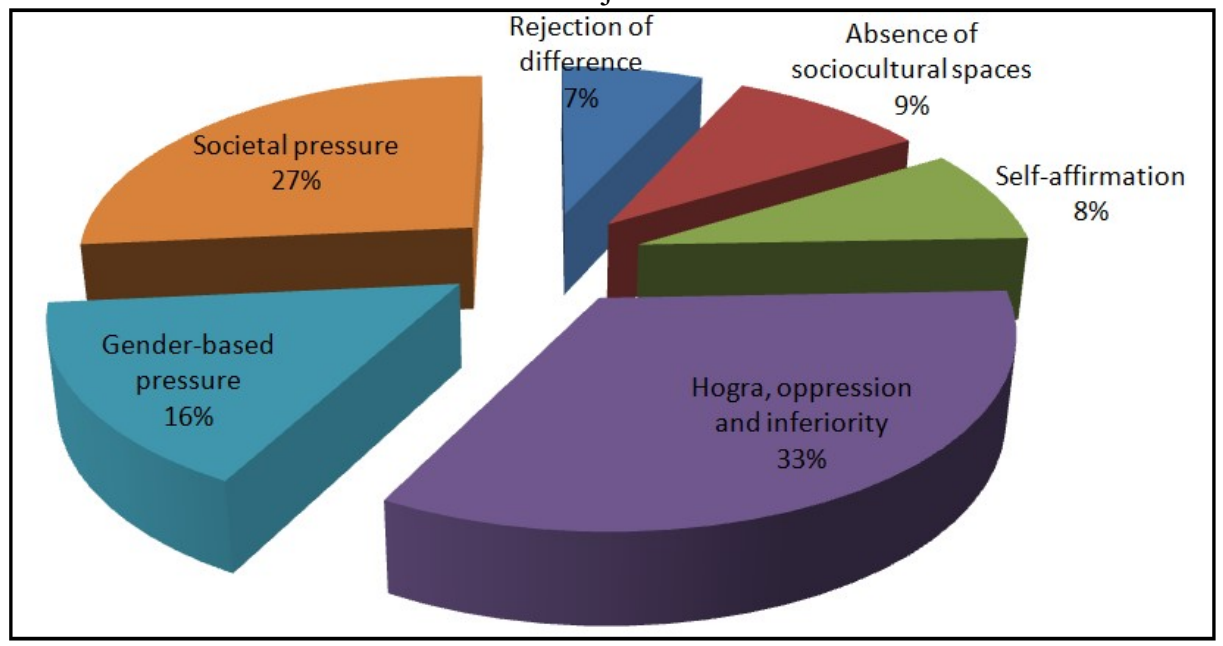

Fig. 2 Living conditions and society/public sphere

It is noteworthy that the contextual realities shape the meanings of the experience of being young. The self-portrayal of their exclusion reveals the supremacy of identity issues. Significantly, their feelings of injustice, oppression, and inferiority termed 'Horgra' supersede other social constraints of gender discrimination. Youth's sense of identity is not an outcome of an inward manufacturing process, but an interactive mechanism of engineering interests, choices, and decisions vis-à-vis social structures and state apparatuses. The epitome of Hogra casts light on youth's ability to express their voice and attain their rights within the family and the school as individuals and their collective rights as citizens by participating in political and civic life.

The study understands the term 'Hogra' as a highly recurrent and predominant signifier of socio-economic, political, or cultural marginalities. It epitomizes the feelings, attitudes, and conditions of oppression and inferiority alongside the exclusion from the sources of wealth and power. Social pressure puts the spotlight on how youth question the validity of dominant social norms, traditions, and the values regulating public life / personal codes. Such perception symbolizes a search for freedom of expression, of being, and acting.

The Arab-uprisings and the mounting protest culture among youth reflect a certain lack of inclusive vision within state and society apparatuses. Their quest for freedom to act raises the question of the availability of structures and institutions that provide space for youth to express their worldviews fully and creatively. Youth call for 'voice' or the freedom to establish their participatory modes in public life within associations, NGOs, clubs, sport, artistic, cultural, civic, and political structures [9]. Youth expressively ask for inclusive policies that could promote the wellbeing of such a vibrant category of Moroccan society [9] to overcome their socio-economic, cultural, and political closure restraining their active citizenship

\section{Agency politics of youth in the margin}


Social studies consider the question of 'agency' and 'structure' as inextricably linked categories [25]. In early theoretical writings on agency, Weber talks about it as a 'rational social action' with instrumental and rational-value motives. This social-rational conceptual duality refers to the relationship between intrinsically legitimate ends or 'intentionality' and the instrumentally rational efficient means to put action into practice [17].. Parsons brings legitimacy to the realm of action through a system of culturally correlated means and ends [27]. Alternatively, Habermas proposes a communicative action as a new kind of social action through patterns of social interaction and mutual understanding. Such a process entails a de-instrumentalizing action, which provides legitimacy to the norms via communication and evades the dominance of power structures [11]. Sociologically, 'agency' is construed as the capacity of individuals to act by choice independently from the factors of influence that limit the agents' decisions like gender, religion, customs, ethnicity, etc. [4]. A more nuanced conception comprehends agency in terms of a temporal process based on the elements of iteration or reactive action, projectivity that visualizes the agents' hopes and aspirations, and a practical evaluation, a capacity to judge among alternatives [21]. Hewson's triple typology of individual, proxy, and collective agency emphasizes three properties that produce agency: being goal-oriented 'intentionality, abilities or resources 'power', and rationality to guide actions [16].

As the realities of exclusion reveal, Moroccan youth are seeking visibility and voice. The collected data has showcased youth's aspirations for change to overcome multifaceted exclusion and discrimination. Significantly, 55\% of our participants and interviewees set forth their willingness to conduct change and participate outside the formal institutions via protest movement, 'artivism' and e-activism to mobilize for action and gain influence locally and nationally [8].

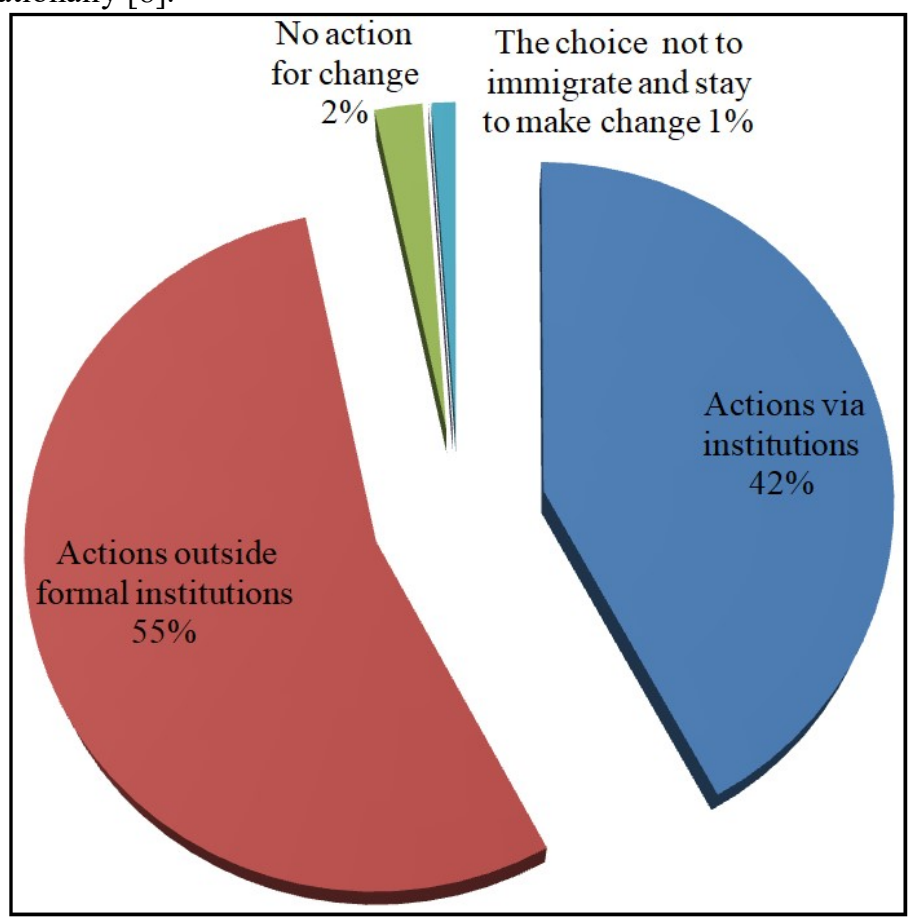

Fig. 3 Types of action for change 
This orientation does not exclude action inside formal institutions via political participation, voting, bidding for elections, affiliating to a political party, or religious, political, cultural, and other organizations. I contend that this expressed intention does not supersede their position of a certain 'standby-ism' characterizing youth participation in formal political and civic action. Their attitude unveils, as many interviews reveal, a "fossilized lack of trust in formal institutions", be they state apparatuses, political parties, or civil society organizations. They attribute to their authoritarian nature and the modes of their interaction with the circle of authority and influence'. Young people display a strong willingness to change, repressed, however.

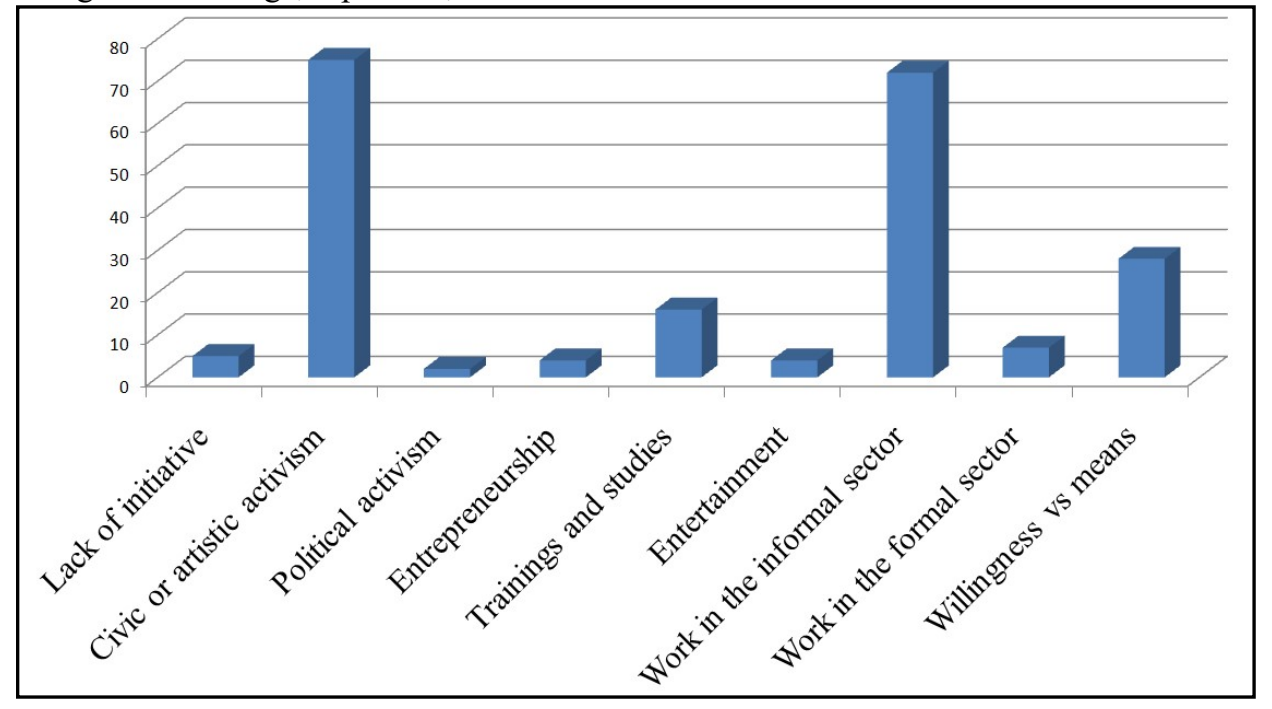

Fig 4 . Nature of youth initiatives to improve personal conditions

The fieldwork analysis reveals the extent to which youth perceive their action as individual agents. The sense of intentionality looks higher while access to power lacks impetus due to exclusion from cultivating resources [16]. The power of agency resides in its dimensionality. For 'agency' to flourish, the attainment of personal goals aspires to satisfy immediate needs and paves the ground for the dimension of public aims using communicative action to realize collective or individual projects without self-limiting changes on the structures. [16]. The social transformation is broader in vision and effect. To allow youth to induce change, collective projects impacting social, political, and cultural awareness might lead to a thoroughgoing change. 


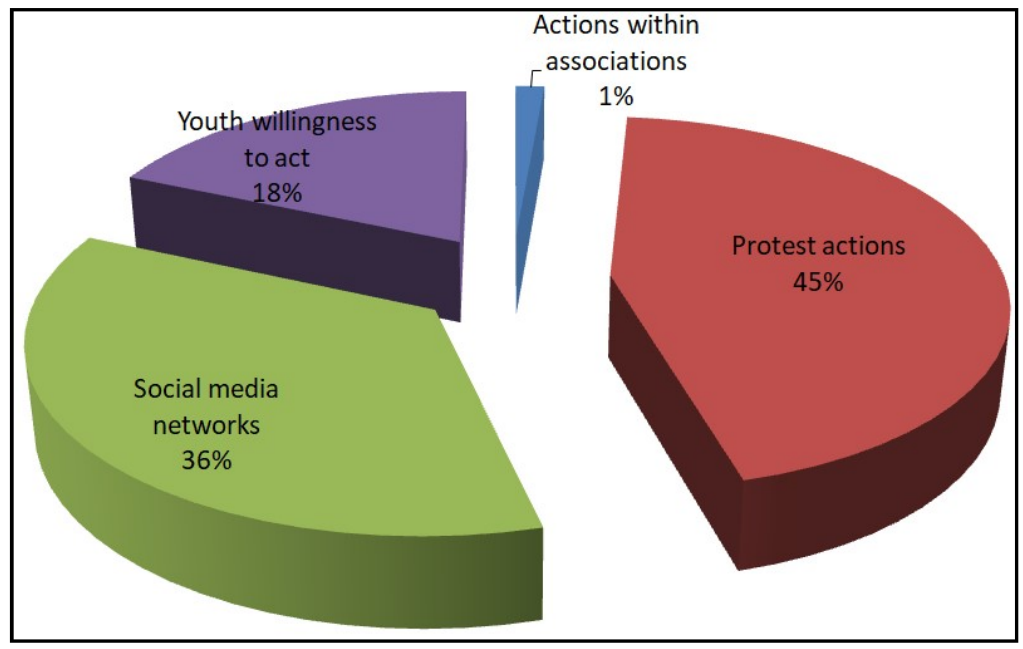

Fig 5 . Modes of influence on public policies

Productive interaction between society and the state takes full-fledged manifestation through the access to and the appropriation of the public sphere as " arenas of public discourse » $[11,3]$. Subsequently, through protest action and contestation movement, or the 'Ihtijaj', youth's current response to marginalization, Hogra, and vertical violence constitutes latent advocacy for visibility, participation in public life, and access to the means of power. In this respect, the Hirak movement in the North and the East, the mounting youth-led boycott culture, and their use of digitized means of social mobilization constitute alternative modes of advocacy young people in the margin deploy to inhabit the center. As the graph shows, in response to the weak involvement of youth in conventional political practice, new social networks and alternative modes of participation could enhance their participation in public life. Put differently, the new communication and global cultural industry offer more inclusive, open, and non-hierarchical tools of action. In sum, the fieldwork has illustrated that the potential of youth agency requires a 'contextual understanding of youth experience' through which individual and collective agency interfaces interactively with social structures' [25].

\section{Conclusion}

This qualitative fieldwork analysis provides an understanding of youth agency from below. It analyzes how youth in the margin are seeking change to gain access to material and symbolic resources. The modes of action they opt for to cope with the conditions of marginalization and violence reveal the 'projective' nature of their agency [4]. Therefore, such projectivity [21]. allows them to indulge in imagining possible future trajectories to escape the structural constraints of the neoliberal economy, neo-authoritarian polity, and social control $[12 ; 14]$. The range of social actions they suggest seems to escape the mere 'reiteration [16].' of past patterns used to respond to typical situations. Instead, their agentive subjectivity emanates from their hopes and dreams for a more inclusive society. More importantly, youth seems to be goal-oriented agents with a strong 'intentionality' to take action and make a change. As Hewson explains, three properties give rise to agency: intentionality, power, and rationality [15]. What would activate this potential of social action is 'power' by developing abilities and mobilizing resources. Following these 
pathways would enhance youth's active participation in the public sphere, cultivate new forms of participation, and influence decision-making public policies.

\section{References}

$1 \quad$ A.Bayat. The Arab Spring and its surprises. Development and Change, 44(3), 587601. (2013). https://doi.org/10.1111/dech.12030

2 A. Maghraoui “Depoliticization in Morocco” J.O.D” 24-32 (2002)

3 A. O. Hirschman. Exit, Voice, and the State. W.P, Vol. 31, No. 1, pp. 90-107 (Oct 1978), Cambridge University. http://www.jstor.org/stable/2009968.

4 C. Barker. Cultural Studies: Theory and Practice. London: Sage. p448 (2005) ISBN 07619-4156-8 7

5 HCP. Activité-emploi et chômage : premiers resultats annuel (2019)

https://www.hcp.ma/downloads/Activite-emploi-et-chomage-premiers-resultatsannuel_t13036.html.

6 HCP. Le marché du travail au Maroc : défis et opportunités. (2017). https://www.hcp.ma/downloads/Le\%20marché\%20du\%20travail\%20au\%20Maroc\%2 0_\%20Défis\%20et\%20opportunités\%20(2)

7 H. Markus. Post Islamism and Fields of Contention After the Arab Spring: Feminism, Salafism, and the Revolutionary Youth. T. W Q, 38(8), 1800-1815. (2017). https://doi.org/10.1080/01436597.2016.1233492

8 I.Martin "The Work o the Street: Street Art and Visual Culture" in The H.V.C, ed. B. Sandywell, I. Heywood. London and New York: Berg, 235-278 (2012)

9 I.Sadoqi. Youth and Cultural Exclusion / Inclusion in Morocco: Patterns and Prospects. Proceedings of the international conference on the challenges to social inclusion in Morocco. December 5, 2015, Rabat, Morocco (2015)

10 I.Sadoqi. Patterns of youth exclusion and violence in Morocco: research note. APSA MENA Workshops: Alumni e-Newsletter. Issue 2, 12-15 Spring (2017) http://web.apsanet.org/mena/wp-content/uploads/sites/6/2016/11/APSA-MENANewsletter.-Issue-2.

11 J. Habermas. The theory of communicative action. Boston: Beacon Press, (1984)

12 K.Bogaert, \& M.Emperador. Imagining the state through social protest: State reformation and the mobilizations of unemployed graduates in Morocco. M.P, 16, 2, 241-259 (2011). https://doi.org/10.1080/13629395.2011. 583741

13 L. Herrera. Wired Citizenship: Youth learning and activism in the Middle East. Routledge (2014).

14 N.Sika.: Beyond the Impasse? Dynamics of youth agency in times of crisis, M.P, (2020 DOI: 10.1080/13629395.2020.1749803

15 L. Zaki, 2007. Séduction électorale au bidonville : jouer de l'opulence, de la jeunesse ou du handicap à Casablanca. P.A. 3 ( $\mathrm{N}^{\circ}$ 107) (2007)

16 M. Hewson. Agency. In A. Mills, G. Durepos, \& E. Wiebe (Eds.), Encyclopedia of case study research. (pp. 13-17). Thousand Oaks, CA: SAGE Publications, Inc. (2010).

17 M. Weber "The Nature of Social Action.", Runciman, W.G. 'Weber: Selections in Translation, Cambridge University Press (1991) 
18 N.Sika. Neoliberalism, marginalization and the uncertainties of being young: The case of Egypt. M.P 24(5), 245-567 (2019). https://doi.org/10.1080/ 13629395.2018.1434067

19 M.Sukarieh \& S. Tannock. Youth rising? The politics of youth in the global. New York: Routledge. (2015).

20 M .Bennani-Charaïbi. Beyond structure and contingency: Toward an interactionist and sequential approach to the 2011 uprisings. M.E.C, 26(4), 373-395, (2017). https://doi.org/10.1080/19436149.2017.136353

21 M..Emirbayer, A. Mische"What Is Agency?". A.J.O.P.H. 103 (4): 962-1023, January (1998). doi:10.1086/231294. ISSN 0002-9602. S2CID $\underline{39562300}$

22 M. Ottaway, A. Hamzawy. Protest movements and political change in the Arab World. Retrieved August 5, 2016, from Carnegie Endowment For International Peace Policy Outlook at https://carnegieendowment.org/2011/01/28/protest-movements-andpolitical-change-in-arab-world-pub-42394

23 M. Valbjørn. (2015). Reflections on self-reflections - on framing the analytical implications of the Arab uprisings for the study of Arab politics. Democratization, 22(2), 218-238. https://doi.org/10.1080/13510347.2015.1010808

24 R.Bourqia ,M.El Ayadi, El Har ras, M. R. Hassan. Jeunes et valeurs religieuses. Casablanca: Éditions Eddif. ( 2000)

25 R. White, J Wyn. Youth agency and social context. JOS. 34,. 3, November (1998)

26 T.Belghazi \& M. Madani. L'action collective au maroc: de la mobilisation des ressources à la prise de parole. Rabat: Publications de la faculté de lettres (2001)

27 T. Parsons. The structure of social action. : a study in social theory with special reference to a group of recent European writers. New York: Free Press (1968). 